\title{
Türkiye Mobilya Sektörü Dış Ticaret Verilerinin Yapay Sinir Ağları İle Değerlendirilmesi
}

\author{
Erol IMREN ${ }^{1 *}$, Bülent KAYGIN ${ }^{1}$, Selman KARAYILMAZLAR ${ }^{1}$ \\ ${ }^{1}$ Bartın Üniversitesi, Orman Fakültesi, Orman Endüstri Makimaları ve İşletme ABD, 74100, BARTIN.
}

Öz

Çalışmada Türkiye mobilya sektörü dış ticaretinin farklı ekonometrik yöntemler ile modellemesi ve projeksiyonu amaçlanmıştır. Bu amaçla Türkiye mobilya dış ticaretinin, ekonomi parametreleri ile arasındaki ilişki incelenerek yapay sinir ağları (YSA) ile tahminde bulunulmuştur. Çalışma verilerinin elde edilmesinde 1969-2018 yıllarına ait Türkiye mobilya sektörü dış ticaret değerlerinden yararlanılmıştır. Mobilya ihracat ve ithalatının gelecek yıllarda değişimi üzerine varsayımlarda bulunularak mobilya sektöründe nasıl bir yol izleneceğine dair çözüm yolları araştırılmıştır. Yapılan analiz sonucunda reel değerlerde mobilya ihracat ve ithalat verilerinde artış olacağı görülmüştür.

Anahtar Kelimeler: Mobilya Sektörü, dış ticaret, yapay sinir ağı.

\section{Evaluation of Foreign Trade Data of Turkish Furniture Industry with Artificial Neural Networks}

\begin{abstract}
In the study, it is aimed to model and project the foreign trade of the Turkish furniture sector with different econometric methods. For this purpose, the relationship between Turkey's furniture foreign trade and economy parameters has been examined and an estimation has been made with artificial neural networks (ANN). In obtaining the study data, the foreign trade values of the Turkish furniture sector for the years 1969-2018 were used. By making assumptions about the change in furniture exports and imports in the coming years, solutions were searched for how to follow a path in the furniture industry. As a result of the analysis, it has been seen that there will be an increase in furniture export and import data in real values.
\end{abstract}

Keywords: Furniture industry, foreign trade, artificial neural networks. 


\section{Giriş}

Mobilya üretiminde ağaç malzeme, plastik malzeme, cam malzeme, metal malzeme ve yardımcı malzemeler kullanılarak ayrı ayrı veya bir konsept oluşturularak yapılabilen, insanoğlunun ihtiyaçları doğrultusunda yemek yeme, oturma, yatma, eşya koyma ve çeşitli şekillerde değerlendirme amacı ile insanların yaşamında kolaylık sağlayan önemli bir malzemedir (Alan 1998; Özlüsoylu ve İstek 2015).

Mobilya sektörü dinamik bir sektördür. Teknolojinin gelişmesi, yeni tasarımlar, malzemeler, tüketici zevk ve tercihlerinin değişmesi vb. etmenlere göre sürekli değişim göstermektedir. Dünyada yaşanan ekonomik ve sosyal gelişmeler büyük şehirlerde kalite algısını değiştirmiş, fonksiyonel ve modern mobilyaya olan talebi arttırmış̧ır. Mobilya sektöründeki talep artışı anlamlı kentsel dönüşüm projeleri, nüfus artışı, yaşam standartlarının yükselmesi ve dış ticaretteki artışa bağlı olarak değişmektedir.

Mobilya sektörü teknolojideki gelişmelere paralel olarak kendisini sürekli geliştirmektedir. Dolayısıyla üretimi kolay olmayan, yüksek maliyetli ürünlerine rağmen her geçen gün ortaya çıkan yeni tasarım ve ürün modellerinin geliştirilmesiyle birlikte daha çok talep gören bir sektör olarak karşımıza çıkmaktadır (Kurt, 2019a).

Mobilya sektörü birçok sektör ile yakın ilişki içerisindedir. Bu nedenle ülke ekonomilerinde lokomotif bir sektör olarak kabul edilmektedir. Bu sektör tarafindan oluşturulan katma değer, istihdam, ihracat, ekonomik büyüme, ticaret hacmi ve vergi geliri gibi faktörler sektörün ülke ekonomisindeki önemini artırmaktadır (İmren vd. 2016).

Ahşap ve mobilya endüstrisinde tüm dünyada yoğun bir rekabet olduğu görülmektedir. Mobilya sektörü ülkelerin ekonomik ve sosyal kalkınmasını destekleyen bir özelliğe sahiptir. Dış ticaret rakamlarına göre ekonomik etkinin istikrarlı biçimde arttığı gözlenmektedir.

Son yıllarda Türkiye mobilya ve orman ürünleri endüstrisi dış ticarette kapasitesini artıracak seviyelere gelmiştir. Gelinen bu seviyede mobilya ve orman ürünleri üretimi yapan ana sanayi firmaları ve yanı sıra yan sanayicilerin (ağaç, metal, tekstil vb.) de önemli payı bulunmaktadır. Mobilya üretimine bağlı olarak, Türkiye son yıllarda özellikle mobilya endüstrisinde görülen gelişme ve büyümeye paralel olarak, yonga levha ve lif levha endüstrilerinde de önemli yatırımlar yapmış, üretim ve ihracat miktarları artış göstermiştir (İstek vd., 2017). Artan rekabet karşısında ekonomik ölçekte ve dünya standartlarında üretim yapan tesisler kurulmuş ve bayilik teşkilatlarıyla mobilyacılık sektörü, bütün ülkelerin dış ticaretinde önemli kalem olan büyük bir sektör konumuna gelmiştir (Anonim, 2014; Bashimov, 2017).

Akbal (2015) yılında yaptığı araştırmaya göre, Dünya mobilya ihracatı incelendiğinde \%31'lik oranla Çin ilk sıradır. Çin'i sırasıyla Almanya \%10, İtalya \%7, Polonya \%5, ABD \%5 ve Kanada \%2'lik oranlarla izlemektedir. Türkiye mobilya ihracatında 15 . sırada yer almaktadır. Dünya mobilya ithalatının yaklaşık \%50'sini sırasıyla ABD $\% 23$, Almanya $\% 10$, Fransa $\% 6$, Birleşik Krallık \%5 ve Kanada \%4'lük oranlarla gerçekleştirmiştir. Türkiye ise mobilya ithalatında 26. sirada yer almaktadır (Akbal, 2015).

$\mathrm{AB}$ ülkeleri mobilya üretimi ve ticareti konusunda diğer ülkelere göre sektörde önemli bir yere sahip olup özellikle mutfak mobilyaları ve döşenmiş mobilyada liderliği ellerinde bulundurmaktadır. Özellikle Almanya ve İtalya hem üretim hem ithalat ve hem de tüketim konusunda diğer Avrupa ülkelerine göre daha güçlü bir konumdadır (Sakarya ve Doğan, 2016).

Türkiye mobilya sektörü, dıș ticaret ve ekonomik dalgalanmalarda kazandığı deneyimle büyük bir potansiyel ve dinamizm kazanmıştır. Toplam ihracatın $\% 33$ ve ithalatın \%50' den fazlası Avrupa Birliği (AB) ülkeleri ile yapılmaktadır. Dolayısıyla oluşan bu bölgesel yoğunluk, sektörün uzun dönemli hedefleri için alternatif pazarların bulunması ihtiyacı doğurmaktadır (Ticaret Bakanlı̆̆ı, 2018).

1996 yılında imzalanan Gümrük Birliği anlaşması ile mobilya ithalatında daha önceki yıllara oranla hızlı bir artış olmuştur. Mobilya ithalatı, 2001 yılında yaşanan ekonomik krizin etkisiyle önceki yıla göre \%40 oranında azalmıştır. 2003 yılı sonunda ithalat yaklaşı 182 milyon dolar düzeyinde olmuştur. 2002 yılındaki küçük artıştan sonra, ekonomide gelişen olumlu duruma bağlı olarak artışıı 2009 yılındaki küresel krize kadar sürdürmüştür. 2009 yllında bir önceki yıla oranla ithalat \%37 değer kaybederek 568 milyon dolara düşmüştür. 2011 yllında mobilya ithalatı verileri 2008 y1lı değerini geçerek yaklașık 941 milyon dolar seviyesinde gerçekleștirmiștir. 2015 yılından sonra ise ithalat değeri azalarak 850 milyon dolar seviyesine, 2016 y1lında da \%28 azalarak 605 milyon dolara seviyesine düşmüştür. Bu durum dış ticaret fazlasını olumlu yönde etkilemektedir.

Dünyada gerçekleşen toplam mobilya ticareti 2017 yılında ihracatta 181,5 milyar dolar, ithalatta ise 179,5 milyar dolar olarak gerçekleşmiştir. Artan rekabet ve tüketim ortamında 2050 yılına kadar dünya mobilya pazarında gerçekleşecek toplam ticaretin 1 trilyon doları geçeceği öngörülmektedir.

Türkiye ekonomisinin bir parçası olan Türkiye mobilya sektörünün dış ticaret yapısını ve toplam dış ticaretini değerler üzerinden belirlemeyi amaçlayan bu çalışmada, sektörün geleceğe dönük finansal ve ekonomik değerleri dünya bankası deflatörleri kullanılarak reel hale getirilmiş ve ekonomik modeller oluşturularak anlatılmıştır. 
Gelecek yönelik mobilya dış ticaret projeksiyonuna bağlı olarak elde edilen değerler üzerinden tahminler yapılmıştır.

Çalışmanın analiz kısmında gerçek yaşamda kullanılan ve başarı oranı yüksek olan YSA modeli oluşturulmuştur. Yapay zekâ çalışmalarının bir ürünü olan, "Yapay Sinir Ağları (YSA)" insan beyninin özelliklerinden olan öğrenme yolu ile yeni bilgiler türetebilme, yeni bilgiler oluşturabilme ve keşfedebilme gibi yetenekleri herhangi bir yardım almadan otomatik olarak gerçekleştirmek amacı ile geliştirilen bilgisayar sistemleridir (Akaytay, 2010; Kurt, 2018). İnsan zayıflıklarını (açlık, yorgunluk, duygusal bozulma, vb.) göz ardı ederek, YSA ile insan beyninin gerçekleştirebileceği birçok süreç kolayca gerçekleştirilebilir (Aytekin, 2017). YSA ile sınıflandırma, modelleme, veri ilişkilendirme-yorumlama, kontrol, kümeleme, optimizasyon gibi birçok farklı alanda yaygın bir şekilde kullanılmaktadır. Tahmin alanında YSA incelendiğinde Aiken vd. (1995); Haas vd. (1995); Kiartzis vd. (1995); Chiang vd. (1996); Gately (1996); Kariniotakis vd. (1996); Zhang vd. (1998); Kolehmainen vd. (2001); Ho vd. (2002); Pijanowski vd. (2002); Niska vd. (2004); Güngör vd (2004); Çuhadar ve Kayacan (2005), Elminir vd. (2005); Hamzaçebi (2005); Doğan (2006); Güngör (2007); Kunt (2007); Pindoriya vd. (2008); Hadavandi vd. (2010); Aslay (2013); Şahin vd. (2013); Masaebi (2016); Kurt vd. (2017); Kurt ve Karayılmazlar (2019), Kurt (2019b) tarafından YSA'nın üretim, pazarlama, finans, borsa, ziraat, orman, gıda, enerji, bankacılık, otomotiv, havacılık gibi birçok farklı alanlarda yaygın bir şekilde kullanıldı̆̆ 1 görülmektedir.

\section{Materyal ve Metot}

\subsection{Materyal}

Çalışmada kullanılan Türk mobilya sektörüne ait dış ticaret verileri 1969 yılından 2018 yılına kadar yıllık ticaret verileridir. Bu verilerin yanı sıra, ekonomiye olan etkiyi karşılaştırabilmek için aynı yılları kapsayan Gayri safi yurt içi hasıla (GSYİH) verilerinden yararlanılmıştır. Bu karşılaştırma yapılırken mobilya üretiminde hammadde olarak kullanılan panellerin üretim miktarları da Birleşmiş Milletler Gıda ve Tarım Örgütü (FAO) veri tabanından almıştır. GSYİH etkisi olan ekonomik büyüme, tüfe, dolar kuru ve nüfus gibi değişkenlere ait veriler Dünya Bankası, Birleşmiş Milletler veri tabanları kullanılarak veri setine dahil edilmiştir. Mobilya üretiminde önemli yeri olan endüstriyel tomruk üretim değerleri, odun temelli paneller, lif levha ve yonga levha üretim değerleri tablo 1 de verilmiştir.

Tablo 1. Endüstriyel tomruk üretim değerleri, odun temelli paneller, lif levha ve yonga levha üretim miktarları (FAO, 2019).

\begin{tabular}{|c|c|c|c|c|c|c|c|c|c|}
\hline Yillar & $\begin{array}{c}\text { End. Tom. } \\
\text { Üretimi } \\
\left(\mathrm{m}^{3}\right)\end{array}$ & $\begin{array}{l}\text { Od. Tem. } \\
\text { Panel }\left(\mathrm{m}^{3}\right)\end{array}$ & $\begin{array}{c}\text { Lif } \\
\text { Levha } \\
\left(\mathbf{m}^{3}\right)\end{array}$ & $\begin{array}{c}\text { Yonga } \\
\text { Levha } \\
\left(\mathrm{m}^{3}\right)\end{array}$ & Yillar & $\begin{array}{l}\text { End. Tom. } \\
\text { Üretimi }\left(\mathbf{m}^{3}\right)\end{array}$ & $\begin{array}{c}\text { Od. Tem. } \\
\text { Panel }\left(\mathbf{m}^{3}\right)\end{array}$ & $\begin{array}{l}\text { Lif Levha } \\
\qquad\left(\mathrm{m}^{3}\right)\end{array}$ & $\begin{array}{c}\text { Yonga } \\
\text { Levha } \\
\left(\mathrm{m}^{3}\right)\end{array}$ \\
\hline 1969 & 4.624 .000 & 160.000 & 46.000 & 79.000 & 1994 & 9.211 .000 & 1.095 .000 & 120.000 & 898.000 \\
\hline 1970 & 4.871 .000 & 165.000 & 38.000 & 89.000 & 1995 & 10.745 .000 & 1.449 .000 & 131.000 & 1.243 .000 \\
\hline 1971 & 5.058 .000 & 173.000 & 38.000 & 94.000 & 1996 & 10.229 .000 & 1.555 .000 & 301.000 & 1.193 .000 \\
\hline 1972 & 5.620 .000 & 196.000 & 39.000 & 119.000 & 1997 & 9.773 .000 & 2.368 .000 & 574.000 & 1.728 .000 \\
\hline 1973 & 6.422 .000 & 218.000 & 40.000 & 139.000 & 1998 & 9.979 .000 & 1.932 .000 & 357.000 & 1.525 .000 \\
\hline 1974 & 7.320 .000 & 258.000 & 43.000 & 177.000 & 1999 & 10.065 .000 & 2.026 .000 & 348.000 & 1.643 .000 \\
\hline 1975 & 6.577 .000 & 325.000 & 45.000 & 240.000 & 2000 & 10.429 .000 & 2.353 .000 & 422.000 & 1.884 .000 \\
\hline 1976 & 6.482 .000 & 390.000 & 53.000 & 292.000 & 2001 & 9.976 .000 & 2.085 .000 & 386.000 & 1.664 .000 \\
\hline 1977 & 7.272 .000 & 452.000 & 63.000 & 339.000 & 2002 & 11.191 .000 & 2.654 .000 & 600.000 & 1.999 .000 \\
\hline 1978 & 7.863 .000 & 531.000 & 63.000 & 415.000 & 2003 & 10.729 .000 & 3.131 .000 & 810.000 & 2.264 .000 \\
\hline 1979 & 6.934 .000 & 540.000 & 70.000 & 425.000 & 2004 & 11.225 .000 & 3.763 .000 & 1.003 .000 & 2.700 .000 \\
\hline 1980 & 6.224 .000 & 436.000 & 70.000 & 332.000 & 2005 & 11.202 .000 & 4.696 .000 & 1.742 .000 & 2.890 .000 \\
\hline 1981 & 6.878 .000 & 436.000 & 70.000 & 332.000 & 2006 & 12.253 .000 & 4.905 .000 & 2.100 .000 & 2.750 .000 \\
\hline 1982 & 6.878 .000 & 434.000 & 70.000 & 330.000 & 2007 & 13.674 .000 & 5.364 .000 & 2.200 .000 & 3.047 .000 \\
\hline 1983 & 5.903 .000 & 469.000 & 85.000 & 330.000 & 2008 & 14.462 .000 & 5.518 .000 & 2.226 .000 & 3.181 .000 \\
\hline 1984 & 6.135 .000 & 681.000 & 70.000 & 546.000 & 2009 & 14.252 .000 & 5.400 .000 & 2.950 .000 & 2.320 .000 \\
\hline 1985 & 5.958 .000 & 771.000 & 70.000 & 636.000 & 2010 & 15.695 .000 & 6.510 .000 & 3.300 .000 & 3.060 .000 \\
\hline 1986 & 7.422 .000 & 771.000 & 70.000 & 636.000 & 2011 & 16.423 .000 & 7.320 .000 & 3.585 .000 & 3.580 .000 \\
\hline 1987 & 6.309 .000 & 771.000 & 70.000 & 636.000 & 2012 & 17.701 .000 & 7.981 .000 & 3.915 .000 & 3.875 .000 \\
\hline 1988 & 6.309 .000 & 771.000 & 70.000 & 636.000 & 2013 & 16.762 .000 & 8.716 .000 & 4.300 .000 & 4.225 .000 \\
\hline 1989 & 5.728 .000 & 771.000 & 70.000 & 636.000 & 2014 & 18.535 .000 & 9.550 .000 & 4.900 .000 & 4.425 .000 \\
\hline 1990 & 5.960 .000 & 771.000 & 70.000 & 636.000 & 2015 & 20.008 .000 & 9.344 .000 & 4.792 .000 & 4.361 .000 \\
\hline 1991 & 5.502 .000 & 771.000 & 70.000 & 636.000 & 2016 & 20.389 .000 & 9.486 .000 & 5.084 .000 & 4.202 .000 \\
\hline 1992 & 8.458 .000 & 1.121 .000 & 100.000 & 947.000 & 2017 & 19.462 .000 & 9.272 .000 & 4.806 .000 & 4.286 .000 \\
\hline 1993 & 9.408 .000 & 1.055 .000 & 95.000 & 883.000 & 2018 & 22.466 .000 & 9.512 .000 & 4.970 .000 & 4.355 .000 \\
\hline
\end{tabular}

Türkiye mobilya sektörü dış ticareti ürünleri 821 ve 872.4 STIC kodları kullanılarak Birleşmiş milletler veri tabanından alınmıştır (COMTRADE 2019). Mobilyaya ait dış ticaret verileri cari olduğundan reel verilerin elde 
edilmesi için dünya bankasına ait dolar 2010 yılı bazlı deflatörü kullanılmıştır (WBG, 2019).

Tablo 2. 1997-2018 cari fiyatlarda mobilya ihracat-ithalat değerleri (COMTRADE, 2019).

\begin{tabular}{llllll}
\hline YIL & İhracat(\$) & Ithalat(\$) & YIL & íhracat(\$) & İthalat(\$) \\
\hline $\mathbf{1 9 9 7}$ & 92.356 .187 & 170.703 .665 & $\mathbf{2 0 0 8}$ & 1.387 .060 .618 & 776.302 .547 \\
$\mathbf{1 9 9 8}$ & 112.286 .307 & 191.232 .820 & $\mathbf{2 0 0 9}$ & 1.198 .406 .234 & 567.681 .121 \\
$\mathbf{1 9 9 9}$ & 142.761 .644 & 160.079 .950 & $\mathbf{2 0 1 0}$ & 1.414 .675 .148 & 738.496 .228 \\
$\mathbf{2 0 0 0}$ & 180.152 .342 & 202.701 .722 & $\mathbf{2 0 1 1}$ & 1.658 .378 .769 & 941.391 .141 \\
$\mathbf{2 0 0 1}$ & 198.409 .079 & 122.791 .423 & $\mathbf{2 0 1 2}$ & 1.898 .571 .570 & 817.334 .996 \\
$\mathbf{2 0 0 2}$ & 290.971 .872 & 130.079 .293 & $\mathbf{2 0 1 3}$ & 2.237 .247 .212 & 968.655 .882 \\
$\mathbf{2 0 0 3}$ & 456.035 .563 & 182.399 .993 & $\mathbf{2 0 1 4}$ & 2.421 .401 .202 & 991.675 .323 \\
$\mathbf{2 0 0 4}$ & 610.740 .599 & 296.078 .271 & $\mathbf{2 0 1 5}$ & 2.256 .503 .946 & 850.638 .052 \\
$\mathbf{2 0 0 5}$ & 715.149 .522 & 389.098 .745 & $\mathbf{2 0 1 6}$ & 2.233 .794 .135 & 605.773 .495 \\
$\mathbf{2 0 0 6}$ & 798.585 .277 & 540.354 .085 & $\mathbf{2 0 1 7}$ & 2.360 .406 .090 & 614.781 .124 \\
$\mathbf{2 0 0 7}$ & 1.081 .913 .376 & 711.956 .560 & $\mathbf{2 0 1 8}$ & 2.686 .665 .713 & 592.840 .380 \\
\hline
\end{tabular}

Verilerin reel hale getirebilmek amacıyla 2010 yılı baz alınarak deflatör kullanılmış ve reel değeri üzerinden hesaplamalar yapılmıştır. Deflatör verileri, dünya bankası veri tabanından yer alan dolar deflatörüdür (Tablo 3).

Tablo 3. Dünya Bankası dolar deflatörü (WBG, 2019).

\begin{tabular}{|c|c|c|c|c|c|c|c|c|c|}
\hline YILLAR & DEFLATÖR & YILLAR & DEFLATÖR & YILLAR & DEFLATÖR & YILLAR & DEFLATÖR & YILLAR & DEFLATÖR \\
\hline 1969 & 0,14 & 1979 & 0,40 & 1989 & 0,32 & 1999 & 0,52 & 2009 & 0,91 \\
\hline 1970 & 0,12 & 1980 & 0,31 & 1990 & 0,41 & 2000 & 0,52 & 2010 & 1,00 \\
\hline 1971 & 0,10 & 1981 & 0,31 & 1991 & 0,41 & 2001 & 0,41 & 2011 & 0,97 \\
\hline 1973 & 0,15 & 1983 & 0,25 & 1993 & 0,43 & 2003 & 0,57 & 2013 & 0,97 \\
\hline 1974 & 0,20 & 1984 & 0,22 & 1994 & 0,33 & 2004 & 0,67 & 2014 & 0,91 \\
\hline 1975 & 0,23 & 1985 & 0,24 & 1995 & 0,40 & 2005 & 0,76 & 2015 & 0,79 \\
\hline 1978 & 0,29 & 1988 & 0,27 & 1998 & 0,55 & 2008 & 1,02 & 2018 & 0,62 \\
\hline
\end{tabular}

\subsection{Yöntem}

YSA'nın kullanılabilir olması ve geleceğe yönelik tahmin yapabilmesi için bağımsız değişkenlere ait gelecek değerlerin de bilinmesi gerekmektedir. Bu çalışmada kullanılan değerler gelecek 10 yıl için (2028 yılına kadar) tahmin değerleri zaman serilerine bağlı olarak bulunmuş ve bu rakamlar üzerinden projeksiyon gerçekleştirilmiştir. ARIMA ile tahminde ise ilk olarak zaman serisinin durağanlık testleri yapılmış ve durağan hale getirildikten sonra en uygun model belirlenerek tahmin işlemi gerçekleştirilmiştir. Tahmin performansları için MSE değerleri hesaplanmıştır. Tahmin için uygulanan YSA modeli olarak, literatürde yaygın biçimde kullanılan Çok Katmanlı Algılayıcı (ÇKA) kullanılmıştır. ÇKA, harici verileri alan bir giriş katmanı, ağın çıktısını veren bir çıkış katmanı ve ikisi arasında en az bir gizli katmandan oluşur. (Hamzaçebi, 2008; Akcan ve Kartal, 2011; Kurt vd., 2017). ÇKA'lar katmanlar arasında tam bağlantı bulunan, ileri beslemeli ve danışmanlı olarak eğitilen ağlardır (Haykin, 2009; Beale vd., 2010: Kurt vd., 2017). Çalışmadaki tüm YSA modellerde ÇKA yararlanılmıştır. YSA uygulamasında her bir girdi verisi (değişkeni), kendisi dışındaki diğer verilerden oluşmaktadır. Örneğin, İthalat ve ihracat tahmin değerleri için yonga levha üretim, lif levha üretim, odun temelli panel üretimi, endüstriyel odun üretimi, nüfus, döviz kurları, GSYİH, TÜFE girdi değişkeni olarak kullanılmıştır.

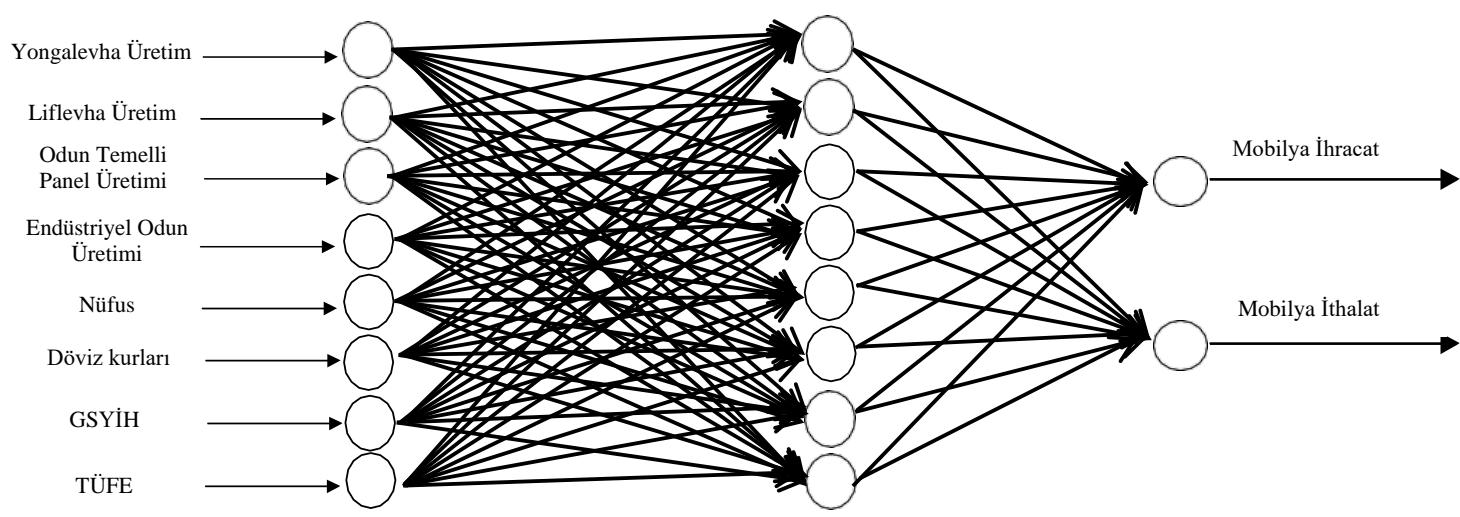

Şekil 1. Mobilya dış ticaret YSA modelinin mimarisi 
Problemin yapısına göre araştırmacı katman sayısında değişik yapabilir. Araştırmacıların çoğu kurdukları ağda ileriye dönük tahminler için tek gizli katman kullanmayı tercih etmişlerdir (Cybenko, 1989; Hornik vd., 1989). Gizli katmandaki nöron sayısının belirlenmesinde sabit bir kural bulunmamaktadır. Ağda öğrenme probleminin çıkmasına genellikle gizli nöron sayısının düşük tutulması neden olmaktadır. Yüksek tutulmasında ise ağın öğrenme yerine ezberlemesine neden olabilmektedir. Dolaysıyla modellerde gizli nöron sayısını belirleyebilmek için 1-10 arasında denemeler yapılmıştır. Nöron sayılarının belirlendikten sonra veriler programa aktarılarak ağın eğitimine başlanmamıştır. Böylece ağın öğrenmesi sağlanmaktadır. Çevrim sayısı sabit bırakılarak her bir model için 0,1-0,9 değerleri arasında değişik varyasyonlar denenmiş ve en uygun momentum ve öğrenme katsayı değerleri bulunmaya çalışılmıştır. Dolayısıyla kurulacak olan modelin optimum sonuç vermesi sağlanmıştır.

Girdi katmanında kullanılan bağımsız değişkenlerin ileriye dönük değerleri için ARIMA (Box-Jenkins) yöntemi ile tahmin edilerek yeniden normalizasyona tabi tutulmuş ve geleceğe ait değerler tahmin edilmiştir. Performans ölçütü olarak literatürde sıklıkla tercih edilen Ortalama Hata Kareleri (MSE), kullanılmıştır (Denklem 1). Her bir ölçütün kendine göre kısıtlamaları olduğu için, herhangi bir problemin çözümünde birden fazla performans ölçütü kullanılabilmektedir (Gentry vd., 1995).

$M S E=\frac{\sum_{i=1}^{n}\left(y_{i}-\hat{y}_{i}\right)^{2}}{n}$

Burada; $y_{i}$ gerçek gözlem değerleri, $\hat{y}_{i}$ Tahmin edilen değerleri ve $n$ yapılan temsil sayısını temsil etmektedir. Hataların kareleri ile elde edilen pozitif değerler toplandıktan sonra ortalamaları alınarak MSE bulunur. MSE istatistik hesaplamalarda sıkça kullanılmaktadır (Kurt, 2018).

\section{Bulgular}

Bağımsız değişkenlerin ARIMA ile tahmininde, yöntemin önemli varsayımlarından biri olan durağanlık koşulunu sağlamak için bazı verilerde logaritmik dönüşüm ve fark alma işlemi gerçekleştirilmiştir. Verilerdeki mevsimsel faktörün etkisi kaldırıldıktan sonra en uygun ARIMA modelleri belirlenmiş ve tahmin işlemi gerçekleştirilmiştir. 1969-2018 yıllarını kapsayan değerlere göre kurulan ARIMA modellerine göre yapılmıştır. Kurulan modellere ait Box-Pierce ki-kare istatistikleri incelendiğinde modelin \%5 anlam seviyesinde tutarlı olduğu ve tahmin için kullanılabileceği görülmektedir. Bu modellerdeki değerler incelendiğinde en uygun model mobilya ihracatında $\operatorname{ARIMA}(1,2,5)$, mobilya ithalatı için $\operatorname{ARIMA}(3,2,5)$ olmaktadır.

Tablo 4. ARIMA(3,2,5) ve ARIMA(1,2,5) modelleri Box-pierce ki-kare sonuçları.

\begin{tabular}{|c|c|c|c|c|c|c|c|c|c|}
\hline \multicolumn{6}{|c|}{ ARIMA(3,2,5) } & \multicolumn{4}{|c|}{ ARIMA $(1,2,5)$} \\
\hline Tip & Katsayılar & Standart Hata & $\mathbf{T}$ & $\mathbf{P}$ & Tip & Katsayılar & Standart Hata & $\mathbf{T}$ & $\mathbf{P}$ \\
\hline AR1 & $-0,064$ & 0,174 & $-0,37$ & 0,716 & AR1 & $-0,832$ & 0,132 & $-6,28$ & 0,000 \\
\hline AR2 & 0,048 & 0,260 & 0,19 & 0,853 & MA1 & 0,470 & 0,221 & 2,13 & 0,039 \\
\hline AR3 & $-0,522$ & 0,246 & $-2,12$ & 0,040 & MA2 & 0,9025 & 0,0869 & 10,39 & 0,000 \\
\hline MA1 & 0,902 & 0,126 & 7,16 & 0,000 & MA3 & $-0,261$ & 0,201 & $-1,30$ & 0,201 \\
\hline MA2 & $-0,117$ & 0,304 & $-0,38$ & 0,702 & MA4 & $-0,267$ & 0,162 & $-1,65$ & 0,107 \\
\hline МАЗ & $-0,443$ & 0,433 & $-1,02$ & 0,313 & MA5 & 0,246 & 0,171 & 1,44 & 0,158 \\
\hline MA4 & 0,468 & 0,366 & 1,28 & 0,209 & Constant & $-0,01767$ & 0,00285 & $-6,21$ & 0,000 \\
\hline MA5 & 0,311 & 0,219 & 1,42 & 0,163 & & & & & \\
\hline Constant & $-0,01960$ & 0,00429 & $-4,56$ & 0,000 & & & & & \\
\hline \multicolumn{10}{|c|}{ Box-pierce (Ljuing box) ki-kare istatistikleri } \\
\hline Lag (Gecikme) & 12 & 24 & 36 & 48 & Gecikme & 12 & 24 & 36 & 48 \\
\hline Ki-kare & 7,54 & 14,42 & 23,51 & * & Ki-kare & 6,04 & 12,90 & 16,02 & * \\
\hline SD & 3 & 15 & 27 & $*$ & SD & 5 & 17 & 29 & $*$ \\
\hline P-Değeri & 0,056 & 0,494 & 0,657 & $*$ & P-Değeri & 0,302 & 0,743 & 0,975 & $*$ \\
\hline
\end{tabular}


Tablo5. Bağımsız Değişkenlerin Tahmin Değerleri

\begin{tabular}{lccccccccc}
\hline YILLAR & $\begin{array}{c}\text { Yonga } \\
\text { levha } \\
\text { üretim }\end{array}$ & $\begin{array}{c}\text { Lif } \\
\text { levha } \\
\text { üretim }\end{array}$ & $\begin{array}{c}\text { Odun } \\
\text { temelli } \\
\text { panel } \\
\text { üretim }\end{array}$ & $\begin{array}{c}\text { Endüstriyel } \\
\text { odun } \\
\text { üretim }\end{array}$ & Nüfus & GSYIH & TÜFE & $\begin{array}{c}\text { Mobilya } \\
\text { ithalat }\end{array}$ & $\begin{array}{c}\text { Mobilya } \\
\text { ihracat }\end{array}$ \\
\hline $\mathbf{2 0 1 4}$ & 15,1988 & 15,4472 & 16,020 & 16,6701 & 18,1625 & 27,6411 & 4,872 & 20,6528 & 21,5010 \\
$\mathbf{2 0 1 5}$ & 15,1933 & 15,5523 & 16,054 & 16,6384 & 18,1800 & 27,6884 & 4,898 & 20,5496 & 21,4083 \\
$\mathbf{2 0 1 6}$ & 15,2149 & 15,7310 & 16,089 & 16,6815 & 18,1976 & 27,7264 & 4,925 & 20,5213 & 21,4398 \\
$\mathbf{2 0 1 7}$ & 15,2211 & 15,8769 & 16,120 & 16,6611 & 18,2155 & 27,7725 & 4,971 & 20,4859 & 21,5195 \\
$\mathbf{2 0 1 8}$ & 15,2832 & 16,0590 & 16,152 & 16,7147 & 18,2336 & 27,8121 & 5,034 & 20,3792 & 21,5912 \\
$\mathbf{2 0 1 9}$ & 15,3179 & 16,2372 & 16,183 & 16,7047 & 18,2520 & 27,8574 & 5,093 & 20,3141 & 21,5813 \\
$\mathbf{2 0 2 0}$ & 15,3382 & 16,4327 & 16,213 & 16,7690 & 18,2705 & 27,8983 & 5,137 & 20,1967 & 21,5314 \\
$\mathbf{2 0 2 1}$ & 15,3650 & 16,6353 & 16,244 & 16,7694 & 18,2894 & 27,9429 & 5,172 & 20,1052 & 21,4648 \\
$\mathbf{2 0 2 2}$ & 15,3647 & 16,8495 & 16,273 & 16,8444 & 18,3084 & 27,9846 & 5,214 & 19,9744 & 21,4202 \\
$\mathbf{2 0 2 3}$ & 15,3730 & 17,0735 & 16,303 & 16,8553 & 18,3277 & 28,0288 & 5,270 & 19,8587 & 21,3747 \\
$\mathbf{2 0 2 4}$ & 15,3837 & 17,3079 & 16,332 & 16,9410 & 18,3472 & 28,0710 & 5,334 & 19,7128 & 21,3194 \\
$\mathbf{2 0 2 5}$ & 15,3867 & 17,5525 & 16,360 & 16,9623 & 18,3669 & 28,1150 & 5,391 & 19,5743 & 21,2336 \\
$\mathbf{2 0 2 6}$ & 15,1988 & 17,8075 & 16,389 & 17,0588 & 18,3868 & 28,1575 & 5,436 & 19,4119 & 21,1302 \\
$\mathbf{2 0 2 7}$ & 15,1933 & 18,0726 & 16,417 & 17,0904 & 18,4069 & 28,2013 & 5,476 & 19,2518 & 21,0119 \\
$\mathbf{2 0 2 8}$ & 15,2149 & 18,3481 & 16,444 & 17,1976 & 18,4271 & 28,2441 & 5,525 & 19,0721 & 20,8901 \\
\hline
\end{tabular}

D1ş ticaret verileri için eğitime geçilmeden önce program kendi içinde farklı öğrenme ve momentum katsayıları deneyerek karşılaştırmalar yapmaktadır. Bu durum öğrenme performansını etkilediğinden gerekli ve önemlidir. Momentum katsayısı, bir önceki iterasyon değişiminin yeni değişim miktarını etkisidir. Öğrenme katsayısı ise ağırlıkların değişiminin miktarını belirler. Eğer büyük değerler seçilirse çözümler arasında ağın dolaşması, küçük değerlerde ise öğrenme zamanını artmasına neden olmaktadır (Öztemel, 2016). İhracat için ağın öğrenme bilgileri, ağdaki çevrim sayısı (epoch) 1000, öğrenme katsayısı 0,5 ve momentum katsayıs1 0,7’ dir.

Ağın eğitimi sonucunda ihracat verileri için her iterasyondaki eğitim, doğrulama ve test kümelerine ait hata değerlerinin değişimi, eğitim durumu ve regresyon değerlerini gösteren grafikler gösterilmektedir. Grafiklerde regresyon değerlerinin eğitim, doğrulama ve test basamaklarında \%98 üzerinde görülmektedir. Giriş verilerinin ağdaki çevrim sayısı 973, en iyi MSE değeri de 0,39405 olarak belirlenmiştir (Şekil 2). 

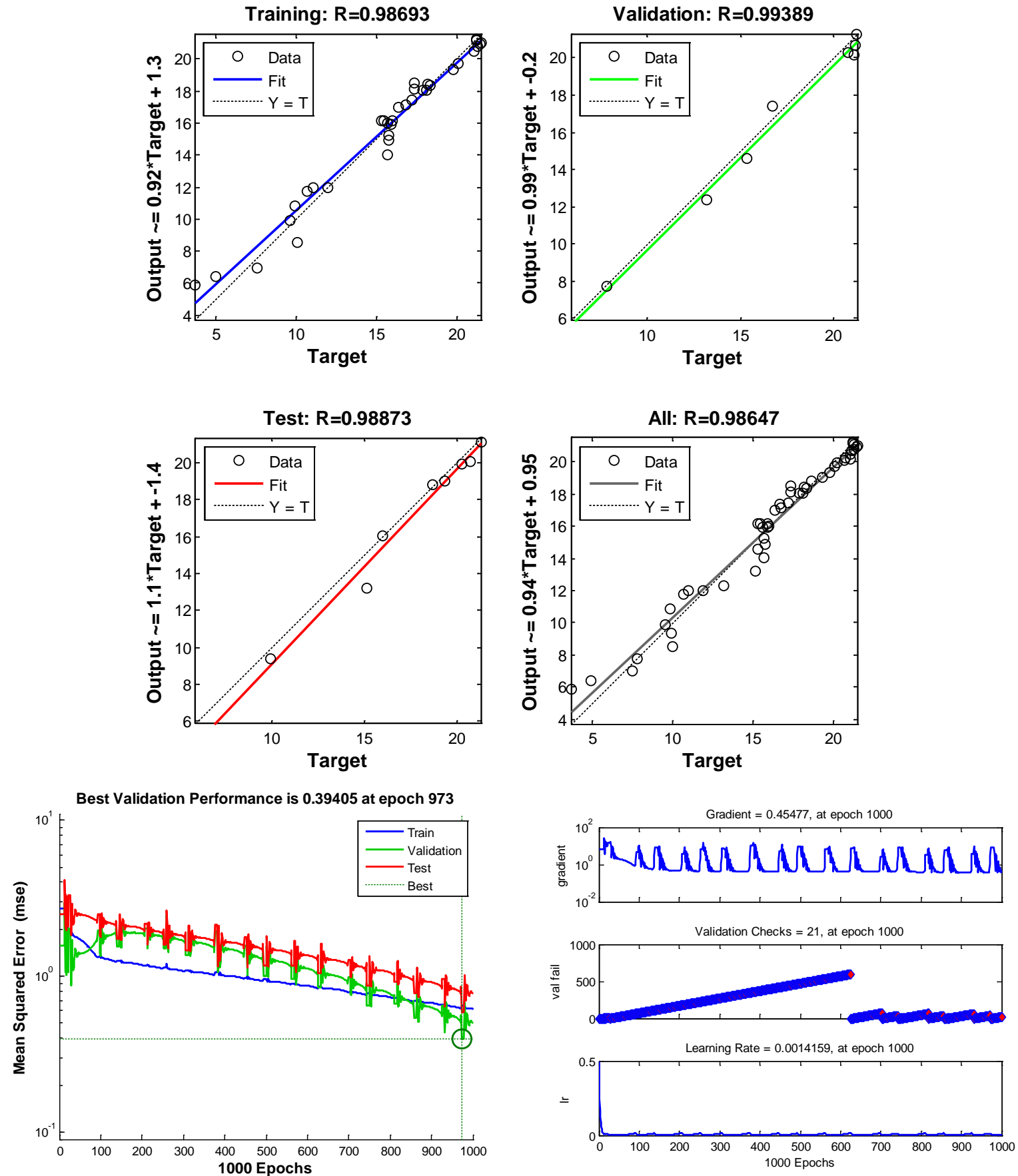

Şekil 2. İhracat değerlerinin YSA performans değerleri

İthalat verilerine ait YSA modelinde ağın öğrenme bilgileri toplam 1000 çevrim sayısı, öğrenme katsayısı 0,2 ve momentum katsayısı 0,4 olarak belirlenmiştir. Ağın eğitimi sonucunda ithalat değerlerine ilişkin grafik görseli şekil 3 incelendiğinde regresyon değerlerinin tüm basamaklarda \%97 nin üzerinde olduğu görülmektedir. En iyi MSE değeri olan 0,38304' te ağdaki çevrim sayısı 223 olarak belirlenmiştir. 
Training: $\mathbf{R}=\mathbf{0 . 9 8 8 5}$

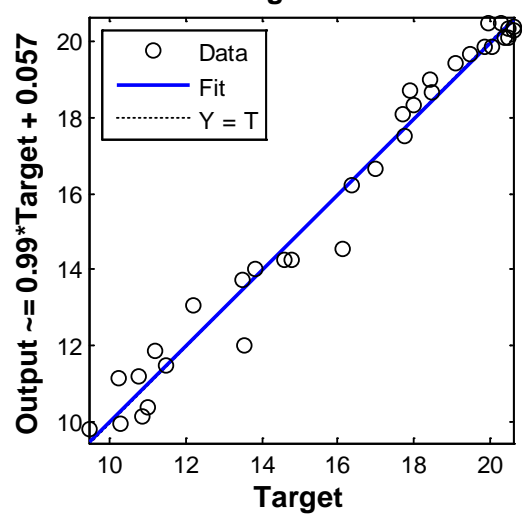

Test: $\mathbf{R}=0.97782$

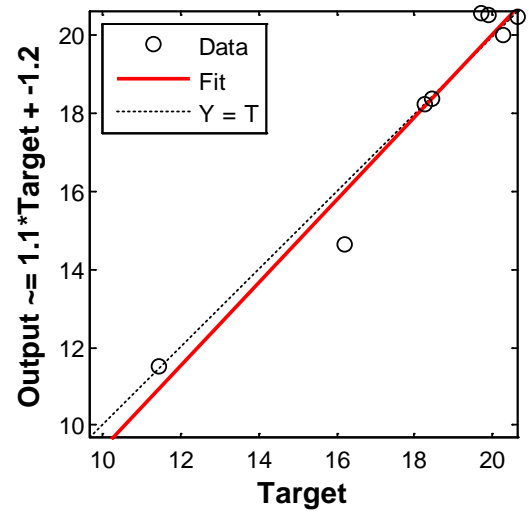

Best Validation Performance is 0.38304 at epoch 223

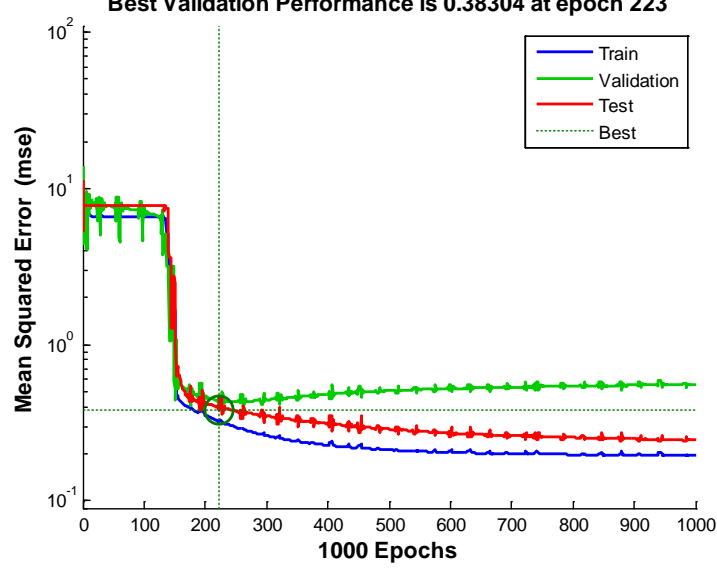

Validation: $\mathrm{R}=0.9747$

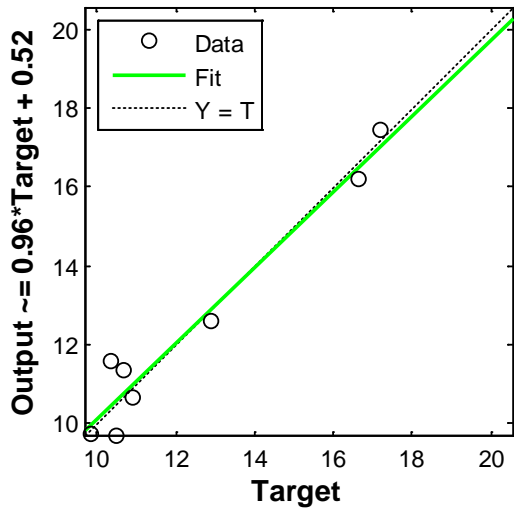

All: $\mathrm{R}=\mathbf{0 . 9 8 8 1 5}$
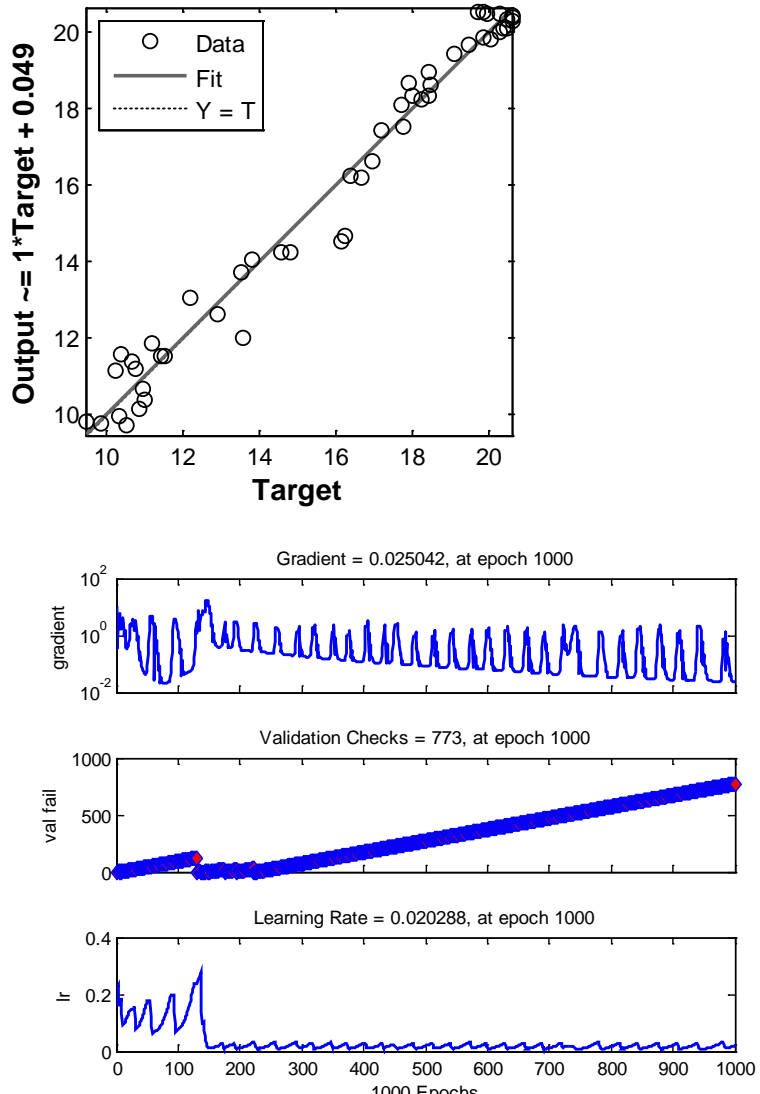

Şekil 4. İthalat değerlerinin YSA performans değerleri

YSA modelinin eğitim, test ve doğrulama işlemlerinden sonra diş ticaret verilerinin tahminine ilişkin değerler tablo 6'da verilmiştir. Tabloya ait verilerin grafikleri şekil 4'de verilmiştir. Tahmini değerlerin gerçek değerlere olan ilişkisini tahmin yöntemlerindeki örneklemiçi 2014-2018 değerleriyle karşılaştırılmış ve YSA analiz tahmin sonuçlarının uygun olduğu görülmüştür. 
Tablo 6. YSA model sonuçları (Mobilya dış ticaret).

\begin{tabular}{ccc}
\hline YILLAR & IHRACAT $(\mathbf{\$})$ & ITHALAT $(\mathbf{S})$ \\
\hline $\mathbf{2 0 1 4} *$ & 1.552 .414 .638 & 752.436 .252 \\
$\mathbf{2 0 1 5}^{*}$ & 1.621 .353 .023 & 767.150 .997 \\
$\mathbf{2 0 1 6}^{*}$ & 1.718 .381 .580 & 784.307 .985 \\
$\mathbf{2 0 1 7} *$ & 1.779 .482 .425 & 797.425 .532 \\
$\mathbf{2 0 1 8} *$ & 1.851 .933 .325 & 815.705 .738 \\
$\mathbf{2 0 1 9}$ & 1.905 .592 .995 & 828.035 .151 \\
$\mathbf{2 0 2 0}$ & 1.963 .547 .773 & 841.463 .365 \\
$\mathbf{2 0 2 1}$ & 2.006 .151 .435 & 851.295 .506 \\
$\mathbf{2 0 2 2}$ & 2.049 .509 .187 & 861.797 .602 \\
$\mathbf{2 0 2 3}$ & 2.081 .219 .933 & 869.234 .778 \\
$\mathbf{2 0 2 4}$ & 2.110 .676 .906 & 878.464 .949 \\
$\mathbf{2 0 2 5}$ & 2.131 .897 .724 & 884.476 .594 \\
$\mathbf{2 0 2 6}$ & 2.150 .525 .572 & 892.159 .465 \\
$\mathbf{2 0 2 7}$ & 2.163 .749 .888 & 897.125 .672 \\
$\mathbf{2 0 2 8}$ & 2.175 .089 .098 & 903.157 .079 \\
\hline
\end{tabular}

YSA Tahmin

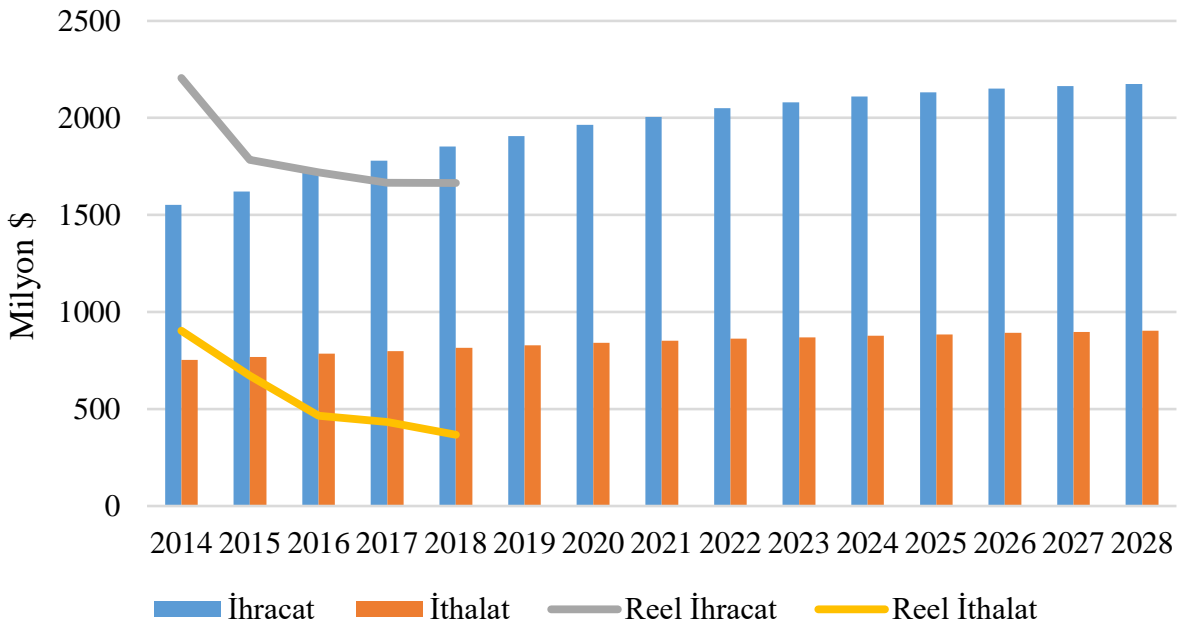

Şekil 4. YSA modelinde diş ticaret değerlerine ait tahmin sonuçları.

\section{Sonuç}

YSA modelinin belirlenmesinde ve ileriye dönük tahminlerde yararlanılacak verilerin \%70'i eğitim, \%15’i doğrulama ve \%15'i test için kullanılmıştır. Tahmin için en uygun YSA modeli kurulmuş ve mobilya dış ticaret tahmini için kurulan YSA modeli değişkenleri olarak Lif levha, yonga levha, odun temelli panel ve endüstriyel odun üretim miktarları $\left(\mathrm{m}^{3}\right)$, Reel GSYİH (\$), döviz kuru, TÜFE, nüfus ve ekonomik büyüme seçilmiştir. YSA modeli olarak tahmin işlemlerinde yaygın olarak tercih edilen ve doğrusal olmayan problemleri başarılı bir şekilde çözüme ulaştırabilen, ileri beslemeli geri yayımlı bir sinir ağı kullanılmıştır. Her değişken için eğitim sırasında en uygun öğrenme ve momentum katsayısı bulunmuştur. YSA tahmin işlemi yapabilmesi için girdi değişkenlerinin gelecek değerlerinin bilinmesi gereklidir. Bu değerler Box-Jernkins yöntemiyle tahmin edilmiştir. İhracata ait YSA uygulamasında eğitim için en iyi öğrenme katsayısı 0,5 ve momentum katsayıs1 0,7 olarak belirlenmiştir. Modelin eğitim, doğrulama ve test aşamalarındaki regresyon değeri \%98 üzerinde ve tahminin MSE değeri 0,39405 olarak hesaplanmıştır. İthalatta ise en iyi öğrenme katsayısı 0,2, momentum katsayısı 0,4 modelin aşamalarındaki regresyon değeri \%97 ve test değerlerinin tutarlılık değeri olan MSE 0,38304 olarak belirlenmiştir. İthalat ve ihracat tahmin değerlerinde 2014-2028 yılları arasında artış görülmektedir.

Türkiye mobilya sektörü ihracat ve ithalat göstergelerine göre, gelişmekte olan ülkeler içerisinde geride bulunmaktadır. Yapılan tahminlere göre Türkiye ekonomik büyüme hızı, önceki yıllara oranla azalma görünümünde olmasına rağmen artış eğiliminde olacağı ve bunun doğal sonucu olarak da mobilya talebinin artacağı gerçeğinden hareketle, imalat sanayi içerisinde en hızlı büyüyen bu sektöre gerekli değerin verilmesinin gereği ortadadır. 
Dış ticaret, sanayileşme politikalarında önemli bir yere sahip olup mobilya sektörünün gelişmesinde de etkisi çok büyüktür. Dolayısıyla mobilya sektörü dış ticaret yapısında zaman içinde meydana gelecek değişimlerin incelenmesi, sektöre ilişkin kısa ve uzun dönemli gelişme, strateji ve politikaların belirlenebilmesi, gelecekte üretim-ithalat-ihracat konularında gerçekçi tahminlerin yapılması gerekliliği son derece önemlidir.

Çalışmanın genelinde mobilya sektörünün dış ticareti yıl bazlı incelenmiştir. Mobilya dış ticaretine etki ettiği düşünülen faktörler reel boyutta ele alınmıştır. Mobilya dış ticaretinin ekonometrik modelleme ile projeksiyonunu konu alan bu çalışmanın, Türkiye mobilya sektöründe yer alan işletmelerin politikalarını dinamik gelişmeler çerçevesinde yenilemelerine olanak sağlamasına katkı sunacağı düşünülmektedir. $\mathrm{Bu}$ sayede sektörün planlamasına referans olması, ülke kaynaklarının daha rasyonel kullanımının sağlanması, mobilya dış ticaretini etkileyen faktörlerin ve mobilya üretim, ithalat, ihracat düzeylerinin belirlenmesi; buna bağlı olarak da hammadde, kapasite, pazarlama, teknoloji, yatırım vb. gibi konularda alınacak tedbirler hususunda fikir vermesi sağlanacaktır.

\section{Kaynaklar}

1. Aiken, M., Krosp, J., Vanjani, M., Govindarajulu, C. Sexton, R. (1995). A neural network for predicting total Industrial production. Journal of End User Computing, 7(2): 19-23.

2. Akaytay, A. (2010). Bağımsız Denetimin Etkinliğini Arttırma Aracı Olarak Yapay Sinir Ağları: Analitik Bir İnceleme. Doktora Tezi, Sakarya Üniversitesi, Sosyal Bilimler Enstitüsü, İşletme Anabilim Dalı, Sakarya, 203 S.

3. Akbal, U. (2015). Dayanıklı Tüketim, Mobilya ve Orman Ürünleri Sektör Raporu 2014. MÜSİAD, 73 s.

4. Akcan, A. ve Kartal, C. (2011). İMKB Sigorta Endeksini Oluşturan Şirketlerin Hisse Senedi Fiyatlarının Yapay Sinir Ağları ile Tahmini. Muhasebe ve Finansman Dergisi, 51(3):27-40.

5. Alan, S. (1998) Mobilya Sektör Raporu (Rapor No-8). Başbakanlık DTM Orta Anadolu İhracatçı Birlikleri Genel Sekreterliği, Ankara.

6. Anonim, (2014). TR63 Bölgesi Mobilyacılık Sektör Raporu, www.dogaka.gov.tr (Erişim Tarihi: 14.05.2016).

7. Aslay, F. (2013). Meteorolojik Parametreler Kullanılarak Yapay Sinir Ağları ile Toprak Sıcaklığının Tahmini. Doktora Tezi, Atatürk Üniversitesi, Sosyal Bilimler Enstitüsü, İşletme Anabilim Dalı, 124 s.

8. Aytekin, A. (2017). Basit düşün, akış diyagramları ile programlama. Detay Yayıncılık, Ankara, $326 \mathrm{~s}$.

9. Bashimov, G. (2017). Mobilya Endüstrisi: Türkiye'nin Küresel Piyasadaki Karşılaştırmalı Üstünlüğü. İktisadi Yenilik Dergisi, 4(2), 20-29.

10. Beale, M.H., Hagan, M.T. ve Demuth, H.B. (2010). Neural network toolbox 7 User's guide. The MathWorks Inc., Natick, MA, $951 \mathrm{s.}$

11. Chiang, W.C., Urban, T.L. ve Baldridge, G.W. (1996). A neural network approach to mutual fund net asset value forecasting. Omega, 24: 205-215.

12. COMTRADE (2019). Birleşmiş Milletler Ticaret Veri Tabanı. https://comtrade.un.org/, (01.12.2019).

13. Cybenko, G. (1989). Approximation by Superposition of A Sigmoidal Function. Mathematical Control Signal Systems, 2: 303-314.

14. Çuhadar, M., ve Kayacan, C. (2005). Yapay Sinir Ağları Kullanılarak Konaklama İşletmelerinde Doluluk Oranı Tahmini: Türkiye'deki Konaklama İşletmeleri Üzerine Bir Deneme. Anatolia: Turizm Arastirmalari Dergisi, 16(1): 24-30.

15. Doğan, V. (2006). Hisse Senedi Getirisinin Yapay Sinir Ağları ile Tahmini. Yüksek Lisans Tezi, Boğaziçi Üniversitesi, Fen Bilimleri Enstitüsü, Sistem ve Kontrol Mühendisliği Anabilim Dalı, İstanbul, 85 s.

16. Elminir, H.K., Areed, F.F. ve Elsayed, T.S. (2005). Estimation Of Solar Radiation Components Incident On Helwan Site Using Neural Networks. Solar Energy, 79: 270-279.

17. FAO (2019). Birleşmiş Milletler Gıda ve Tarım Örgütü Veri Tabanı. http://www.fao.org/faostat, (01.12.2019).

18. Gately, E. (1996). Neural Networks For Financial Forecasting. John Wiley, New York.

19. Gentry, T.W., Wiliamowski, B.M. ve Weatherford, L.R. (1995). A Comparison of Traditional Forecasting Techniques and Neural Networks. Intelligent Engineering Systems Through Artificial Neural Networks, 1995(5): 765-770.

20. Güngör, E. (2007). Yapay Sinir Ağları Yardımı ile Makine Arızalarının Önceden Tahmin Edilmesi. Yüksek Lisans Tezi, Kocaeli Üniversitesi, Sosyal Bilimler Enstitüsü, Kocaeli, 74 s.

21. Güngör, İ., Kayacan, C. ve Korkmaz, M. (2004). Endüstriyel odun hammaddesi talebinin tahmininde yapay sinir ağlarının kullanımı ve bazı tahmin yöntemleri ile karşılaştırılması. Yöneylem Araştırması Endüstri Mühendisliği XXIV. Ulusal Kongresi, Çukurova Üniversitesi, 15-18 Haziran 2004, Adana.

22. Haas, D.J., Milano, J. ve Flitter, L. (1995). Prediction of helicopter component loads using neural networks. Journal of the American Helicopter Society, 40 (1): 72-82.

23. Hadavandi, E., Shavandi, H. ve Ghanbari, A. (2010). Integration of Genetic Fuzzy Systems and Artificial Neural Networks for Stock Price Forecasting. Knowledge-Based Systems, 23: 800-808. 
24. Hamzaçebi, C. (2005). Geleceği Tahminde Yapay Sinir Ağları İçin Sezgisel Öğrenme Algoritmaları. Doktora Tezi, Gazi Üniversitesi, Fen bilimleri Enstitüsü, Endüstri Mühendisliği Anabilim Dalı, 159 s.

25. Hamzaçebi, C. (2008). Improving Artificial Neural Networks: Performance in Seasonal Time Series Forecasting. Information Sciences, 178 (23): 4550-4559.

26. Haykin, S. (2009). Neural Networks and Learning Machine. Pearson Education Inc. New Jersey. 936 s.

27. Ho, S.L., Xie, M. ve Goh T.N. (2002). A comperative study of neural network and box-jenkins ARIMA modeling in time series prediction. Computers and Industrial Engineering, 42(2002): 371- 375.

28. Hornik, K., Stinchcombe, M. ve White, H. (1989). Multilayer feed-forward networks are universial approximators. Neural Networks, 2: 359-366.

29. İmren, E., Karayılmazlar, S., Kurt, R. (2016). Selection of optimal establishment place using AHP (Analytical Hierarchy Process): an application of furniture industry. Bartın Orman Fakültesi Dergisi, 18(2), 48-54. DOI: 10.24011/barofd.267287.

30. İstek, A., Özlüsoylu, İ. ve Kızılkaya, A. (2017). Türkiye Ahşap Esaslı Levha Sektör Analizi. Bartın Orman Fakültesi Dergisi, 19(1):, 132-138.

31. Kariniotakis, G.N., Stavrakakis, G.S. ve Nogaret, E.F. (1996). Wind power forecasting using advenced artificial neural network models. IEEE Transactions on Energy Conversion, 11(4): 762-767.

32. Kiartzis, S.J., Bakirtzis, A.G. ve Petridis, V. (1995). Short-term load forecasting using neural networks. Electric Power Systems Research, 33:1-6.

33. Kolehmainen, M., Martikainen, H. ve Ruuskanen, J. (2001). Neural networks and periodic components used in air quality forecasting. Atmospheric Environment, 35: 815-825.

34. Kunt, F. (2007). Hava Kirliliğinin Yapay Sinir Ağları Yöntemiyle Modellenmesi ve Tahmini. Yüksek Lisans Tezi, Selçuk Üniversitesi, Fen Bilimler Enstitüsü, Çevre Mühendisliği Anabilim Dalı, Konya, 89 s.

35. Kurt, R. (2018). İstatistiksel Süreç Kontrolünde Shewhart, CUSUM ve EWMA Kontrol Kartları ile Yapay Sinir Ağlarının Bütünleşik Kullanımı: Bir Orman Endüstri İşletmesinde Uygulama. Doktora Tezi, Bartın Üniversitesi, Fen Bilimleri Enstitüsü, Orman Endüstri Mühendisliği Anabilim Dalı, Bartın, 234 s.

36. Kurt, R. (2019a). Mobilya Sektöründe E-Ticaret'in GZFT Analizi ile Değerlendirilmesi. Düzce Üniversitesi Bilim ve Teknoloji Dergisi, 7 (1), 616-627. DOI: 10.29130/dubited.485746

37. Kurt, R. (2019b). Determination of the Most Appropriate Statistical Method for Estimating the Production Values of Medium Density Fiberboard. BioResources, 14(3), 6186-6202.

38. Kurt, R., Karayılmazlar, S., İmren, E., Çabuk, Y. (2017). Forecasting by using artificial neural networks: Turkey's paper-paperboard industry case. Bartın Orman Fakültesi Dergisi, 19(2), 99-106. DOI: 10.24011/barofd.334773

39. Kurt, R., ve Karayilmazlar, S. (2019). Estimating Modulus of Elasticity (MOE) of Particleboards Using Artificial Neural Networks to Reduce Quality Measurements and Costs. Drvna industrija: Znanstveni časopis za pitanja drvne tehnologije, 70(3), 257-263.

40. Masaebi, P. (2016). Yapay Sinir Ağları ile İran Elektrik Tüketim Tahmini. Yüksek Lisans Tezi, Karadeniz Teknik Üniversitesi, Fen Bilimleri Enstitüsü, Endüstri Mühendisliği Anabilim Dalı, Trabzon, 75 s.

41. Niska, H., Hiltunen, T., Karppinen, A., Ruuskanen, J. ve Kolehmainen, M. (2004). Evolving the neural network model for forecasting air pollution time series. Engineering Applications of Artificial Intelligence, 17: 159-167.

42. Özlüsoylu, İ. ve İstek, A. (2015). Mobilya Üretiminde Kullanılan Panellerden Salınan Formaldehit Emisyonu ve İnsan Sağlığı Üzerine Etkileri. Selcuk University Journal of Engineering Sciences, 14(2): 213-227.

43. Öztemel, E. (2016). Yapay Sinir Ağları. Papatyabilim Yayıncılık, İstanbul, $232 \mathrm{s.}$

44. Pijanowski, B.C., Brown, D.G., Shellito, B.A. ve Manik G.A. (2002). Using Neural Networks and GIS To Forecast Land Use Changes: A Land Transformation Model. Computers, Environment and Urban Systems, 2002(26): 553-575.

45. Pindoriya, N.M., Singh, S.N. ve Singh, S.K. (2008). An Adaptive Wavelet Neural Network-Based Energy, Price Forecasting in Electricity Markets. IEEE Transactıons On Power Systems, 23(3): 1423-1432.

46. Sakarya, S., ve Doğan, Ö. (2016). Mobilya Sektör Raporu. Orta Anadolu İhracatçı Birlikleri Genel Sekreterliği, Ankara, $36 \mathrm{~s}$.

47. Şahin, M., Büyüktümtürk, F. ve Oğuz, Y. (2013). Yapay Sinir Ağları ile Aydınlık Kalitesi Kontrolü. Afyon Kocatepe Üniversitesi Fen ve Mühendislik Bilimleri Dergisi, 13(2013): 1-10.

48. Ticaret Bakanlığı (2018). Mobilya Sektör Raporu. T.C. Ticaret Bakanlığı İhracat Genel Müdürlüğü, 14 s.

49. WBG (2019). Dünya Bankası Açık Verileri. https://data.worldbank.org/, (11.02.2020).

50. Zhang, G., Patuwo, B.E. ve Hu, M.Y. (1998). Forecasting With Artificial Neural Networks: The State Of The Art. International Journal of Forecasting, 14: 35-62. 